\title{
JUDICIALIZAÇÃO DA SAÚDE E CONTRIBUIÇÕES DA TEORIA DE JUSTIÇA DE NORMAN DANIELS
}

Judicialization of health and contributions of the Norman Daniels' Theory of Justice

${ }^{1}$ Fundação Oswaldo Cruz. Rio de Janeiro/RJ, Brasil.

Correspondência: Teresa Robichez Machado. E-mail: trobichez@yahoo.com.br.

Recebido em: 15/11/2014. Revisado em: 13/05/2015. Aprovado em: 14/05/2015. 


\section{RESUMO}

A temática da judicialização da saúde gera discussão em várias áreas de conhecimento, com contribuições, em especial, de juristas, médicos e gestores públicos. Pela diversidade dos atores envolvidos, a gama de temas tratados é farta. Algumas teses destacam os argumentos positivos da judicialização da saúde, outras defendem a necessidade de se estabelecerem critérios ou limitações à atuação judicial. Outros estudos, ainda, ressaltam preocupações com as possíveis consequências negativas desse processo. No intuito de fundamentar uma análise sobre o tema, este artigo pretende realizar uma revisão bibliográfica e adota o instrumental teórico de Norman Daniels, que propõe uma reflexão sobre as necessidades de saúde e o modo como podemos atendê-las, a importância moral da saúde e a desigualdade de saúde considerada como injusta. Conclusivamente, verifica-se que algumas das teses defendidas no debate nacional não se sustentam perante os dados apresentados. A partir do pensamento de Daniels sobre a Teoria de Justiça voltada às questões de saúde, extrai-se do debate brasileiro que não há muitos conflitos quanto à importância moral especial do tema; além disso, há um silêncio quanto ao segundo aspecto da teoria, que se refere à reflexão sobre quando uma desigualdade de saúde pode ser considerada injusta. Propõe-se conclusivamente que a teoria de Daniels acrescente dois importantes pontos ao debate nacional. O primeiro relaciona-se à necessidade de situar os problemas de saúde dentro de uma reflexão maior sobre políticas públicas. E o segundo, quanto à necessidade de que a fixação de limites para o atendimento de demandas de saúde, encaixa-se em uma política pública que vise a melhor atender às necessidades da população, não sendo uma simples avaliação de custo-benefício.

\section{Palavras-Chave}

Judicialização; Norman Daniels; Saúde; Teoria de Justiça.

\section{ABSTRACT}

The judicialization of health generates debate in various areas of knowledge, with particular contributions from legal experts, doctors, and policymakers. Because of the diversity of those involved, several topics are considered. Some studies highlight positive arguments for the judicialization of health, whereas others defend the need for establishing criteria for or limitations to judicial action. Furthermore, others still report concerns over the possible negative consequences of this process. In order to offer an analysis on this topic, this study provides a review of the literature and adopts the theoretical instrument by Norman Daniels, who proposes a reflection on the needs for health and the ways in which these needs can be met, the moral importance of health and the inequalities in health to be an injustice. In conclusion, it can be affirmed that some of these studies defended in the Brazilian national debate cannot be sustained in light of the data presented herein. Throughout Norman Daniels' thoughts on the Theory of Justice in terms of questions of health, it can be deduced that, in the Brazilian debate, there are few conflicts over the moral importance of the topic; in addition, not much is known about the second aspect of the theory, which is the reflection when inequality in health can be considered unjust. It is therefore proposed that Daniels' theory adds two important points to the national debate. The first involves the need to place health problems within a greater reflection in public policy. The second, which involves the need to establish limits to meeting health demands, fits into a public policy that seeks to better meet the needs of the population, which is not a simple cost-benefit assessment.

\section{Keywords}

Health; Judicialization; Norman Daniels; Theory of Justice. 


\section{Introdução}

A judicialização da saúde tem sido objeto de amplo debate no meio acadêmico. A temática gera discussão em várias áreas de conhecimento, com contribuições, em especial, de juristas, médicos e gestores públicos. Pela diversidade dos atores envolvidos, a gama de temas tratados é farta. Algumas teses são constantes na literatura estudada para este artigo. Entre elas, destacam-se os argumentos que demonstram o aspecto positivo da judicialização da saúde, em especial a garantia de maior acesso dos indivíduos aos serviços de saúde ${ }^{1}$. Ainda

${ }^{1}$ BAHIA, Ligia; COSTA, Nilson Rosário; STRALEN, Cornelis Van. A saúde na agenda pública: convergências e lacunas nas pautas de debate e programas de trabalho das instituições governamentais e movimentos sociais. Ciência \& Saúde Coletiva, v. 12, p. 1791-1818, 2007. Disponível em: <http://www.scielo.br/pdf/csc/v12s0/04.pdf>. http:// dx.doi.org/10.1590/S1413-81232007000700004. CARDOSO, Oscar V. Questões controversas sobre a determinação judicial de fornecimento de medicamentos excepcionais pelo poder público. Revista CEJ - Centro de Estudos Judiciários do Conselho da Justiça Federal, v.13, n. 45, p. 46-55, 2009. DINIZ, Debora; MEDEIROS, Marcelo; SCHWARTZ, Ida Vanessa D. Consequências da judicialização das políticas de saúde: custos de medicamentos para as mucopolissacaridoses. Cadernos de Saúde Pública, v.28, n. 3, p. 479-489, 2012. Disponível em: <http:// www.scielo.br/pdf/csp/v28n3/08.pdf>. http://dx.doi.org/10.1590/S0102-311X2012000300008. LIMA, Viviane M. C. Peregrinação, empoderamento e retrocessos no acesso a medicamentos por via judicial no estado do Amazonas - Brasil. 2009. Dissertação (Mestrado) - Universidade do Vale do Itajaí - Univali, Itajaí, 2009. MACHADO, Marina A. de A. Acesso a medicamentos via Poder Judiciário no Estado de Minas Gerais. 2010. Dissertação (Mestrado) - Universidade Federal de Minas Gerais- UFMG, Belo Horizonte, 2010. MAZZA, Fabio Ferreira. Os impasses entre a judicialização da saúde e o processo orçamentário sob a responsabilidade fiscal: uma análise dos fundamentos decisórios do Supremo Tribunal Federal. 2013. Dissertação (Mestrado) - Faculdade de Saúde Pública, Universidade de São Paulo, São Paulo, 2013. Disponível em: <http://www.teses.usp.br/teses/disponiveis/6/6135/tde-21052013-162419/> . Acesso em: 15 abr. 2014. APPIO, Eduardo. A judicialização da política em Dworkin. Revista Seqüência, n. 47, p. 81-97, dez. 2003. ANDRADE, Eli I. G. et al. A judicialização da saúde e a Política Nacional de Assistência Farmacêutica no Brasil: gestão da clínica e medicalização da justiça. Revista Médica de Minas Gerais, v. 18, n. 4, supl. 4, p. S46-S50, 2008. Disponível em: <http://rmmg.org/artigo/detaIhes/1268>. Acesso em: 25 set. 2015. BAPTISTA, Tatiana W. de F.; MACHADO, Cristiani V.; LIMA, Luciana D. de. Responsabilidade do Estado e direito à saúde no Brasil: um balanço da atuação dos Poderes. Ciência \& Saúde Coletiva, v. 14, n. 3, p. 829-839, 2009. Disponível em: <http://www.scielo.br/pdf/csc/v14n3/18.pdf> http://dx.doi. org/10.1590/S1413-81232009000300018. BORGES, Danielle da C. L.; UGÁ, Maria Alicia D. As ações individuais para o fornecimento de medicamentos no âmbito do SUS: características dos conflitos e limites para a atuação judicial. Revista de Direito Sanitário, v. 10, n. 1, p. 13-38, 2009. Disponível em: <http://www.revistas.usp.br/rdisan/ article/view/13144>. http://dx.doi.org/10.11606/issn.2316-9044.v10i1p13-38. CHAVES, Gabriela C.; VIEIRA, Marcela F.; REIS, Renata. Acesso a medicamentos e propriedade intelectual no Brasil: reflexões e estratégias da sociedade civil. Sur: revista internacional de direitos humanos, v. 5, n. 8, p. 170-198, 2008. Disponível em: <http:// www.scielo.br/pdf/sur/v5n8/v5n8a09.pdf>. http://dx.doi.org/10.1590/S1806-64452008000100009. FIGUEIREDO, Tatiana; PEPE, Vera Lúcia E.; OSORIO-DE-CASTO, Claudia G. S. Um enfoque sanitário sobre a demanda judicial de medicamentos. Physis: revista de saúde coletiva, v. 20, n. 1, p. 101-118, 2010. Disponível em: <http:// www.scielo.br/pdf/physis/v20n1/a07v20n1.pdf>. $\quad$ http://dx.doi.org/10.1590/S0103-73312010000100007. MACHADO, Marina A. de. A. et al. Judicialização do acesso a medicamentos no Estado de Minas Gerais, Brasil. Revista de Saúde Pública, São Paulo, v. 45, n. 3, p. 590-598, 2011. Disponível em: <http://www.scielo.br/pdf/ rsp/v45n3/2403.pdf>. http://dx.doi.org/10.1590/S0034-89102011005000015. MACHADO, Felipe R. de S.; DAIN, Sulamis. A audiência pública da saúde: questões para a judicialização e para a gestão de saúde no Brasil. Revista de Administração Pública, v. 46, n. 4, p. 1017-1036, jul./ago. 2012. Disponível em: <http://www.scielo.br/ pdf/rap/v46n4/a06v46n4.pdf>. http://dx.doi.org/10.1590/S0034-76122012000400006. PANDOLFO, Mércia; DELDUQUE, Maria Célia; AMARAL, Rita G. Aspectos jurídicos e sanitários condicionantes para o uso da via judicial no acesso aos medicamentos no Brasil. Revista de Salud Pública, Bogotá, v.14, n. 2, p. 340-349, mar./abr. 2012. Disponivel em: <http://www.scielosp.org/pdf/rsap/v14n2/v14n2a14.pdf>. http://dx.doi.org/10.1590/S012400642012000200014 . NOGUEIRA, Danielle C. B. A efetivação do direito à saúde: fornecimento judicial de medicamentos. 2011. Dissertação (Mestrado) - Universidade Federal do Maranhão, São Luís, 2011. VENTURA, Miriam et al. Judicialização da saúde, acesso à justiça e a efetividade do direito à saúde. Physis: revista de saúde coletiva, Rio de Janeiro, v. 20, n. 1, p. 77-100, 2010. Disponível em: <http://www.scielo.br/pdf/physis/v20n1/a06v20n1. pdf>. http://dx.doi.org/10.1590/S0103-73312010000100006. 
como benefício do processo de judicialização, alguns autores ressaltam a influência do Poder Judiciário na busca por melhorias e pela eliminação de ineficiências ou falhas encontradas nas políticas públicas ${ }^{2}$. Alguns autores, ainda, defendem a atuação judicial, mas enfatizam a necessidade de que sejam estabelecidos critérios ou limitações a essa intervenção ${ }^{3}$.

De outro lado, alguns estudos ressaltam preocupações com as possíveis consequências negativas da judicialização de questões relacionadas à saúde. Entre os argumentos levantados, destacam-se: (a) limitações orçamentárias ${ }^{4}$; (b) necessidade de decisões coerentes e que observem as diretrizes e políticas públicas, bem como falta de capacitação técnica dos juízes e não observância de critérios de comprovação de eficácia e segurança dos medicamentos (critérios estes analisados no programa de dispensação de medicamentos do Ministério da Saúde) ${ }^{5}$;

${ }^{2}$ CARLINI, Angélica L. Judicialização da saúde pública no Brasil: causas e possibilidades. 2011. Tese (Doutorado) - Universidade Presbiteriana Mackenzie, São Paulo, 2011. PEPE, Vera Lúcia E. et al. A judicialização da saúde e os novos desafios da gestão da assistência farmacêutica. Ciência \& Saúde Coletiva, Rio de Janeiro, v. 15, n. 5, p. 2405-2414, ago. 2010. Disponível em: <http://www.scielo.br/pdf/csc/v15n5/ v15n5a15.pdf>. http://dx.doi.org/10.1590/S1413-81232010000500015. SARTÓRIO, Maria José. Política de medicamentos excepcionais no Espírito Santo: a questão da judicialização da demanda. 2004. Dissertação (Mestrado) - Universidade Federal do Rio Grande do Sul - UFRGS, Porto Alegre, 2004.

${ }^{3}$ BORGES, Danielle da C. L.; UGÁ, Maria Alicia D. Conflitos e impasses da judicialização na obtenção de medicamentos: as decisões de $1^{\mathrm{a}}$ instância nas ações individuais contra o Estado do Rio de Janeiro, Brasil, em 2005. Cadernos de Saúde Pública, São Paulo, v. 26, n. 1, p. 59-69, 2010. Disponível em: <http://www.scielo.br/pdf/csp/v26n1/07.pdf>. http://dx.doi.org/10.1590/S0102-311X2010000100007. BARROSO, Luís R. Da falta de efetividade à judicialização excessiva: direito à saúde, fornecimento gratuito de medicamentos e parâmetros para a atuação judicial. Revista da Procuradoria-Geral do Estado do Rio Grande do Sul, Porto Alegre, v. 31, n. 66, p. 89-114, 2007.

${ }^{4}$ BARBOSA, Mariana G. O STF e a política de fornecimento de medicamentos para tratamento da AIDS/HIV. Revista Jurídica, v. 9, n. 88, 2007. Disponível em: <http://www.planalto.gov.br/ccivil_03/revista/Rev_88/MonoDisTeses/MarianaBarbosa.pdf>. Acesso em: 25 set. 2015. CARLINI, Angélica L. op. cit.; MAZZA, Fabio Ferreira. op. cit.; SARTÓRIO, Maria José. op. cit.; FERRAZ, Octávio L. M.; VIEIRA, Fabiola S. Direito à saúde, recursos escassos e equidade: os riscos da interpretação judicial dominante. Dados: revista de ciências sociais, v.52, n. 1, p. 223-251, 2009. Disponível em: <http://www.scielo.br/pdf/dados/v52n1/v52n1a07.pdf>. http://dx.doi. org/10.1590/S0011-52582009000100007. TANAKA, Oswaldo Y. A judicialização da prescrição medicamentosa no SUS ou o desafio de garantir o direito constitucional de acesso à assistência farmacêutica. Revista de Direito Sanitário, São Paulo, v. 9, n. 1, p. 137-143, 2008. Disponível em: <http://www.revistas.usp.br/rdisan/ article/view/13109>. http://dx.doi.org/10.11606/issn.2316-9044.v9i1p139-143.

${ }^{5}$ BORGES, Danielle da C. L.; UGÁ, Maria Alicia D.. op. cit. CARDOSO, Oscar V. op. cit. LEITE, Silvana N. et al. Ações judiciais e demandas administrativas na garantia do direito de acesso a medicamentos em Florianópolis-SC. Revista de Direito Sanitário, v. 10, n. 2, p. 13-28, 2009. Disponível em: <http://www.revistas.usp.br/rdisan/article/view/13161>. http://dx.doi.org/10.11606/issn.2316-9044.v10i2p13-28. MACHADO, Marina A. de A. op. cit. MACHADO, Marina A. de. A. et al. FIGUEIREDO, Tatiana; PEPE, Vera Lúcia E.; OSORIO-DE-CASTO, Claudia G. S. op. cit. LOPES, Luciane C. et al. Uso racional de medicamentos antineoplásicos e ações judiciais no Estado de São Paulo. Revista de Saúde Pública, v. 44, n. 4, p. 620-628, ago. 2010. Disponível em: <http://www.scielo.br/pdf/ rsp/v44n4/05.pdf>. http://dx.doi.org/10.1590/S0034-89102010000400005. MACEDO, Eloisa I. de; LOPES, Luciane C.; BARBERATO-FILHO, Silvio. Análise técnica para a tomada de decisão do fornecimento de medicamentos pela via judicial. Revista de Saúde Pública, São Paulo, v. 45, n. 4, p. 706-713, 2011. Disponível em: <http:// www.scielo.br/pdf/rsp/v45n4/2603.pdf>. http://dx.doi.org/10.1590/S0034-89102011005000044. PEPE, Vera Lúcia E. et al. Caracterização de demandas judiciais de fornecimento de medicamentos "essenciais" no Estado do Rio de Janeiro, Brasil. Cadernos de Saúde Pública, São Paulo, v. 26, n. 3, p. 461-471, 2010. Disponível em: <http://www.scielo.br/pdf/csp/v26n3/04.pdf>. http://dx.doi.org/10.1590/S0102-311X2010000300004. SANT'ANA, João Mauricio B. et al. Racionalidade terapêutica: elementos médico-sanitários nas demandas judiciais de medicamentos. Revista de Saúde Pública, São Paulo, v. 45, n. 4, p. 714-721, ago. 2011. Disponível em: <http://www.scielo.br/pdf/rsp/v45n4/2517.pdf>. http://dx.doi.org/10.1590/S0034-89102011005000042. VENTURA, Miriam et al. op. cit. TANAKA, Oswaldo Y. op. cit. 
(c) acesso elitizado ao Poder Judiciário ${ }^{6}$; (d) prevalência do interesse individual em detrimento do coletivo ${ }^{7} \mathrm{e}$ (e) influência econômica da indústria farmacêutica na obtenção judicial de medicamentos ${ }^{8}$.

Percebe-se no debate nacional um vazio quanto à discussão do direito à saúde em um contexto mais amplo de justiça, sendo o enfoque muito direcionado a questões pontuais sobre alocação de recursos e a obrigatoriedade ou não do Estado de arcar com os custos de um determinado produto ou serviço de cuidado de saúde. Neste texto, objetiva-se analisar as teses dominantes, em especial as que apresentam embasamento empírico, no intuito de verificar a coerência entre os dados obtidos e a formulação teórica proposta. Será utilizado para tal análise o fundamento teórico de Norman Daniels, o qual propõe uma reflexão sobre três aspectos em relação às necessidades de saúde: (a) se a saúde possui uma importância moral especial; (b) quando uma desigualdade de saúde pode ser considerada injusta; $\mathrm{e}(\mathrm{c})$ como podemos atender às necessidades de saúde se não conseguimos atender a todas as necessidades.

\footnotetext{
${ }^{6} \mathrm{CHIEFFI,} \mathrm{Ana} \mathrm{Luiza;} \mathrm{BARATA,} \mathrm{Rita} \mathrm{B.} \mathrm{Judicialização} \mathrm{da} \mathrm{política} \mathrm{pública} \mathrm{de} \mathrm{assistência} \mathrm{farmacêutica} \mathrm{e} \mathrm{eqüi-}$ dade. Cadernos de Saúde Pública, v. 25, n. 8, p. 1839-1849, 2009. Disponível em: <http://www.scielo.br/ pdf/csp/v25n8/20.pdf>. http://dx.doi.org/10.1590/S0102-311X2009000800020. LIMA, Viviane. op. cit. MACHADO, Marina. op. cit. MACHADO, Marina et al. op. cit. FERRAZ, Octávio L. M.; VIEIRA, Fabiola S. op. cit. ${ }^{7} \mathrm{CHIEFFI}$, Ana Luiza; BARATA, Rita B. op. cit. MAZZA, Fabio. op. cit. SARTÓRIO, Maria José. op. cit. ANDRADE, Eli. op. cit. BAPTISTA, Tatiana; MACHADO, Cristiani; LIMA, Luciana. op. cit. BORGES, Danielle; UGÁ, Maria Alicia. op. cit. MACHADO, Felipe; DAIN, Sulamis. op. cit. TANAKA, Oswaldo. op. cit.

${ }^{8}$ HAYDEN, Cori. Sem patente não há genérico: acesso farmacêutico e políticas de cópia. Sociologias, n. 19, p. 62-91, 2008. Disponível em: <http://seer.ufrgs.br/index.php/sociologias/article/view/5668/3266>. Acesso em: 25 set. 2015. JANNUZZI, Anna H. L.; VASCONCELLOS, Alexandre G.; SOUZA, Cristina G. de. Especificidades do patenteamento no setor farmacêutico: modalidades e aspectos da proteção intelectual. Cadernos de Saúde Pública, v. 24, n. 6, p. 1205-1218, 2008. MEINERS, Constance M. M. de A. Patentes farmacêuticas e saúde pública: desafios à política brasileira de acesso ao tratamento anti-retroviral. Cadernos de Saúde Pública, Rio de Janeiro, v. 24, n. 7, p. 1467-1478, jul. 2008. Disponível em: <http://www.scielo. br/pdf/csp/v24n7/02.pdf>. http://dx.doi.org/10.1590/S0102-311X2008000700002. STAMFORD, Artur; CAVALCANTI, Maísa. Decisões judiciais sobre acesso aos medicamentos em Pernambuco. Revista de Saúde Pública, São Paulo, v.46, n. 5, p. 791-799, out. 2012. Disponível em: <http://www.scielo.br/pdf/rsp/ v46n5/05.pdf>. http://dx.doi.org/10.1590/S0034-89102012000500005. COSTA-COUTO, Maria Helena; NASCIMENTO, Álvaro C. Assimetria nas relações internacionais, propriedade industrial e medicamentos anti-aids. Ciência \& Saúde Coletiva, v. 13, n. 6, p. 1869-1877, 2008. Disponível em: <http://www.scielo. br/pdf/csc/v13n6/a22v13n6.pdf>. http://dx.doi.org/10.1590/S1413-81232008000600022. CHAVES, Gabriela C.; VIEIRA, Marcela F.; REIS, Renata. op. cit. CHAVES, Gabriela C. et al. A evolução do sistema internacional de propriedade intelectual: proteção patentária para o setor farmacêutico e acesso a medicamentos. Cadernos de Saúde Pública, v.23, n. 2, p. 257-267, 2007. Disponível em: <http://www.scielo. br/pdf/csp/v23n2/02.pdf>. http://dx.doi.org/10.1590/S0102-311X2007000200002. CAMPOS NETO, Orozimbo H. et al. Médicos, advogados e indústria farmacêutica na judicialização da saúde em Minas Gerais, Brasil. Revista de Saúde Pública, v.46, n. 5, p. 784-790, 2012. Disponível em: <http://www.scielo.br/ pdf/rsp/v46n5/04.pdf>. http://dx.doi.org/10.1590/S0034-89102012000500004. CHIEFFI, Ana Luiza; BARATA, Rita de Cássia B. Ações judiciais: estratégia da indústria farmacêutica para introdução de novos medicamentos. Revista de Saúde Pública, São Paulo, v. 44, n. 3, p. 421-429, 2010. Disponível em: <http:// www.scielo.br/pdf/rsp/v44n3/05.pdf>. http://dx.doi.org/10.1590/S0034-89102010000300005. SOARES, Jussara C. R. de S.; DEPRÁ, Aline S. Ligações perigosas: indústria farmacêutica, associações de pacientes e as batalhas judiciais por acesso a medicamentos. Physis: revista de saúde coletiva, Rio de Janeiro, v. 22, n. 1, p. 311-329, 2012. Disponível em: <http://www.scielo.br/pdf/physis/v22n1/v22n1a17. pdf>. http://dx.doi.org/10.1590/S0103-73312012000100017.
} 


\section{Metodologia}

No tocante ao levantamento bibliográfico nacional, serão analisados artigos de periódicos científicos, teses e dissertações em bases de dados, utilizando como palavras-chave: judicialização, direito à saúde, serviço público de saúde, orçamento público e alocação de recursos. O levantamento foi realizado nos bancos de dados da Coordenação de Aperfeiçoamento de Pessoal de Nível Superior (Capes), da Biblioteca Digital de Teses e Dissertações (BDTD), do Proquest e do Scientific Electronic Library Online (SciELO). Foram obtidos 168 artigos e 12 teses ou dissertações que tratam do tema saúde e/ou judicialização. Diretamente relacionados ao tema judicialização, foram encontrados 53 documentos nacionais.

Dentre eles, 35 documentos apresentam dados empíricos obtidos em bancos de dados de tribunais ou de órgãos da administração pública responsáveis pela demanda judicial de saúde ${ }^{9}$; cinco artigos cujo objeto de análise foi a revisão

${ }^{9}$ BAPTISTA, Tatiana; MACHADO, Cristiani. op. cit. BARBOSA, Mariana. op. cit. BORGES, Danielle. op. cit. BORGES, Danielle da C. L.; UGÁ, Maria Alicia D. op. cit. CAMPOS NETO, Orozimbo H. et al. op. cit. CARDOSO, Oscar. op. cit. CARLINI, Angélica L. op. cit. CHAVES, Gabriela C.; VIEIRA, Marcela F.; REIS, Renata. op. cit. CHIEFFI, Ana Luiza; BARATA, Rita B. Judicialização da política pública de assistência farmacêutica e equidade, cit. CHIEFFI, Ana Luiza; BARATA, Rita de Cássia B. Ações judiciais: estratégia da indústria farmacêutica para introdução de novos medicamentos, cit. DINIZ, Debora; MEDEIROS, Marcelo; SCHWARTZ, Ida. op. cit. ENGELMANN, Fabiano; CUNHA FILHO, Marcio C. Ações judiciais, conteúdos políticos: uma proposta de análise para o caso brasileiro. Revista de Sociologia e Política, v.21, n. 45, p. 57-72, 2013. FERRAZ, Octávio; VIEIRA, Fabiola. op. cit. GUERRA JR., Augusto A. et al. Disponibilidade de medicamentos essenciais em duas regiões de Minas Gerais, Brasil. Revista Panamericana de Salud Pública, Washington, v. 15, n. 3, p. 168-175, mar. 2004. Disponível em: <http://www.scielosp.org/pdf/rpsp/v15n3/ a05v15n3.pdf>. http://dx.doi.org/10.1590/S1020-49892004000300005. LEITE, Silvana et al. op. cit. LEITE, Silvana N.; MAFRA, Ana Cristina. Que direito? Trajetórias e percepções dos usuários no processo de acesso a medicamentos por mandados judiciais em Santa Catarina. Ciência \& Saúde Coletiva, Rio de Janeiro, v.15, n. 1, p. 1665-1672, 2010. Disponível em: <http://www.scielo.br/pdf/csc/v15s1/078. pdf>. http://dx.doi.org/10.1590/S1413-81232010000700078. LIMA, Viviane. op. cit. LOPES, Luciane. op. cit. MACEDO, Eloisa; LOPES, Luciane; BARBERATO-FILHO, Silvio. op. cit. MACHADO, Marina. op. cit. MACHADO, Marina et al. op. cit. MARQUES, Silvia Badim; DALLARI, Sueli G. Garantia do direito social à assistência farmacêutica no Estado de São Paulo. Revista de Saúde Pública, v. 41, n. 1, p. 101-107, fev. 2007. Disponível em: <http://www.scielo.br/pdf/rsp/v41n1/15.pdf>. http://dx.doi.org/10.1590/S003489102007000100014. MAZZA, Fabio. op. cit. MESSEDER, Ana Márcia; OSORIO-DE-CASTRO, Claudia G. S.; LUIZA, Vera L. Mandados judiciais como ferramenta para garantia do acesso a medicamentos no setor público: a experiência do Estado do Rio de Janeiro, Brasil. Cadernos de Saúde Pública, Rio de janeiro, v.21, n. 2, p. 525-534, mar./abr. 2005. Disponível em: <http://www.scielo.br/pdf/csp/v21n2/19.pdf>. http://dx.doi.org/10.1590/S0102-311X2005000200019. NOGUEIRA, Danielle. op. cit. PEPE, Vera Lúcia E. et al. A judicialização da saúde e os novos desafios da gestão da assistência farmacêutica, cit. PEPE, Vera Lúcia E. et al. Caracterização de demandas judiciais de fornecimento de medicamentos "essenciais" no Estado do Rio de Janeiro, Brasil, cit. SANT'ANA, João Mauricio B. Essencialidade e assistência farmacêutica: um estudo exploratório das demandas judiciais individuais para acesso a medicamentos no Estado do Rio de Janeiro, Fiocruz. 2009. Dissertação (Mestrado) - Fiocruz, Rio de Janeiro, 2009. SANT'ANNA, João Maurício. op. cit. SARTÓRIO, Maria José. op. cit. STAMFORD, Artur; CAVALCANTI, Maísa. op. cit. VENTURA, Miriam et al. op. cit. VIEIRA, Fabiola S.; ZUCCHI, Paola. Distorções causadas pelas ações judiciais à política de medicamentos no Brasil. Revista de Saúde Pública, São Paulo, v. 41, n. 2, p. 214-222, 2007. Disponível em: <http://www.scielo.br/pdf/rsp/v41n2/5587.pdf>. http://dx.doi.org/10.1590/S003489102007000200007. VIANNA, Luiz J. Werneck; BURGOS, Marcelo; SALLES, Paula. Dezessete anos de judicialização da política. Cadernos CEDES, 2006. Disponível em: <http://www.cis.puc-rio.br/cis/cedes/ PDF/09janeiro\%20fevereiro/Caderno\%20no13.pdf>. Acesso em: 25 set. 2015. 
da literatura ${ }^{10}$; seis textos fundamentados em análise de documentos normativos, legislativos ou esparsas decisões judiciais ${ }^{11}$; três que se utilizaram de dados secundários de outros textos ou pesquisas ${ }^{12}$; e quatro eminentemente teóricos ${ }^{13}$.

\section{Instrumental teórico de Norman Daniels}

Para Daniels, a razão do desenvolvimento de teorias éticas gerais, incluindo teorias da justiça, é fornecer um quadro para definir disputas importantes sobre crenças morais. Segundo o autor, uma teoria da justiça relacionada ao direito à saúde deve tratar das responsabilidades individuais e sociais no tocante à proteção e promoção da saúde, devendo tanto abranger a fundamentação teórica como responder às questões reais. Ademais, entende que a discussão sobre o tema não deve ficar restrita aos aspectos de alocação de recursos e serviços de saúde, devendo abranger as grandes determinantes da saúde da população - incluindo renda e riqueza, educação, participação política, distribuição de direitos e poderes, e oportunidade. O fato de a saúde não ser simplesmente produto de cuidados de saúde significa que não podemos facilmente isolar a saúde de uma justiça social mais ampla ${ }^{14}$.

Daniels considera que, para tratar de questões fundamentais sobre a política social e a justiça distributiva, é imprescindível o entendimento das correlações entre os resultados de saúde e as desigualdades sociais. A desigualdade de renda, no entendimento do autor, afeta a saúde e corrói a coesão social, aumentando a desconfiança social e reduzindo a participação em organizações cívicas. Já a falta de coesão social acarreta uma diminuição da participação social na política, minando

\footnotetext{
${ }^{10}$ ACURCIO, Francisco de Assis; GUIMARÃES, Mark Drew Crosland. Acessibilidade de indivíduos infectados pelo HIV aos serviços de saúde: uma revisão de literatura. Cadernos de Saúde Pública, São Paulo, v. 12, n. 2, jun. 1996. Disponível em: <http://www.scielo.br/scielo.php?script=sci_arttext\&pid=S0102-311X1996 000200012\&lng=en\&nrm=iso>. http://dx.doi.org/10.1590/S0102-311X1996000200012. ANDRADE, Eli et al. op. cit. CAMPOS, Célia Maria Sivalli; BATAIERO, Marcel Oliveira. Necessidades de saúde: uma análise da produção científica brasileira de 1990 a 2004. Interface - Comunicação, Saúde, Educação, v. 11, n. 23, p. 605-618, set./dez. 2007. Disponível em: <http://www.scielo.br/pdf/icse/v11n23/a14v1123.pdf>. http://dx.doi.org/10.1590/S1414-32832007000300014; MACHADO, Felipe; DAIN, Sulamis. op. cit. PANDOLFO, Mércia; DELDUQUE, Maria Célia; AMARAL, Rita. op. cit.

${ }^{11}$ BAHIA, Ligia; COSTA, Nilson; STRALEN, Cornelis Van. op. cit. CHAVES, Gabriela et al. op. cit. DALLARI, Sueli G. Controle judicial da política de assistência farmacêutica: direito, ciência e técnica. Physis: revista de saúde coletiva, v. 20, n. 1, p. 57-75, 2010. Disponivel em: <http://www.scielo.br/pdf/physis/v20n1/a05v20n1. pdf>. http://dx.doi.org/10.1590/S0103-73312010000100005. MEINERS, Constance. op. cit. TANAKA, Oswaldo. op. cit. VIEIRA, Fabiola S. Ações judiciais e direito à saúde: reflexão sobre a observância aos princípios do SUS. Revista de Saúde Pública, São Paulo, v. 42, p. 365-369, 2008. Disponível em: <http:// www.scielo.br/pdf/rsp/2008nahead/6847.pdf>. Acesso em: 25 set. 2015.

${ }^{12}$ ASENSI, Felipe D. Judicialização ou juridicização? As instituições jurídicas e suas estratégias na saúde. Physis: Revista de Saúde Coletiva, Rio de Janeiro, v.20, n. 1, p. 33-55, 2010. Disponível em: <http://www. scielo.br/pdf/physis/v20n1/a04v20n1.pdf>. http://dx.doi.org/10.1590/S0103-73312010000100004. FIGUEIREDO, Tatiana; PEPE, Vera Lúcia; OSORIO-DE-CASTRO, Claudia. op. cit. JANNUZZI, Anna; VASCONCELLOS, Alexandre; SOUZA, Cristina. op. cit.

${ }^{13}$ APPIO, Eduardo. op. cit. BARROSO, Luís. op. cit. COSTA-COUTO, Maria Helena; NASCIMENTO, Álvaro. op. cit. HAYDEN, Cori. op. cit.

${ }^{14}$ DANIELS, Norman. Just health: meeting health needs fairly. Cambridge: Cambridge University Press, 2008.
} 
a capacidade de resposta das instituições do governo para atender às necessidades sociais, especialmente dos grupos menos favorecidos. Daniels, então, rebate a invocação da saúde como um direito individual ou humano, pois considera que este raciocínio não ajuda na eliminação das divergências e incertezas sobre o alcance desse direito e não conta com uma justificação adequada para sua reivindicação como direito. Propõe, ao contrário, incluir o direito à saúde no âmbito de uma teoria geral aceitável de justiça ${ }^{15}$.

Em sua teorização, o autor coloca três questões centrais: (a) se a saúde possui uma importância moral especial, o que leva à reflexão sobre como as necessidades de saúde estão relacionadas com outros objetivos de justiça, caracterizando a base da obrigação social de proteger a saúde (em síntese, o autor conclui que a saúde é de especial importância moral porque contribui para o leque de oportunidades dos indivíduos); (b) quando uma desigualdade de saúde pode ser considerada injusta, o que leva à compreensão dos fatores e das políticas sociais que contribuem para as desigualdades na saúde individual e da população, permitindo uma concepção melhor dos fatores que afetam a saúde da população e sua distribuição e obrigando à discussão e proposição de mudanças nas políticas sociais (defende que as desigualdades na saúde são injustas quando resultam de uma distribuição injusta dos fatores socialmente controláveis que afetam a saúde da população, o que inclui sua tese de que não devemos admitir que os infortúnios naturais gerem injustiças); e (c) como podemos atender às necessidades de saúde se não conseguimos atender a todas as necessidades (para tanto, devemos determinar a origem dos nossos acordos e desacordos sobre a definição de prioridades. Se soubermos como estabelecer prioridades justas e legítimas, então poderemos orientar nossas ações em direção aos resultados acordados. Necessidades e preferências não são equivalentes. Uma objeção ao falar de necessidades é a alegação de que não temos o tipo de acordo que nos permite convergir para esse quadro e desenvolver uma lista de necessidades ${ }^{16}$.

Daniels ressalta que mesmo pessoas razoáveis podem discordar sobre o peso de cada uma das necessidades listadas e sobre a forma de gerir os recursos escassos. Parte-se, então, para a busca de um procedimento justo de decisão para a alocação de recursos quando não há consenso sobre as disputas. Algumas condições específicas são imprescindíveis, por exemplo: publicidade de justificativas, possibilidade de revisão das mesmas em razão de novos argumentos, responsabilização dos tomadores de decisão pela razoabilidade de suas decisões e a garantia de que esses requisitos sejam uniformemente aplicados ${ }^{17}$.

Em sua noção de igualdade democrática, influenciada por Rawls, Daniels entende que as desigualdades são permitidas se acarretarem um ganho para os

\footnotetext{
${ }^{15}$ DANIELS, Norman. op. cit.

${ }^{16}$ Id. Ibid.

${ }^{17}$ Id. Ibid.
} 
que estão em pior situação, se comparadas a arranjos alternativos. A controvérsia moral que envolve a criação de vencedores e perdedores nas decisões de alocação de recursos resulta em um problema de legitimidade, na medida em que demanda uma resposta sobre em quais condições os tomadores de decisão têm a autoridade moral para definir os limites impostos por suas decisões. E a pergunta não envolve apenas os atores das decisões, mas também a forma como elas são tomadas, e a necessidade de justificação e publicidade das mesmas. Ao final, Daniels pondera que uma autoridade é razoável como legítima apenas se cumprir um procedimento ou processo previamente determinado e debatido. Se não houver consenso sobre princípios capazes de resolver disputas acerca da alocação de recursos para a saúde e os cuidados de saúde, então é preciso encontrar um processo justo cujos resultados sejam aceitos como justos ou razoáveis ${ }^{18}$.

\section{Revisão da bibliografia nacional sobre judicialização da saúde}

No Brasil, a judicialização da saúde tem sido objeto de debate não só no que se refere às alternativas de processos de tomada de decisão sobre a alocação orçamentária, especialmente no que se refere à insuficiência dos recursos atualmente alocados, como também sobre a desorganização do Estado na definição e implementação das políticas relacionadas ao tema ${ }^{19}$.

\footnotetext{
${ }^{18}$ DANIELS, Norman. op. cit.

${ }^{19}$ BERSUSA, Ana Aparecida Sanches et al. Acesso a serviços de saúde na Baixada Santista de pessoas portadoras de hipertensão arterial e ou diabetes. Revista Brasileira de Epidemiologia, São Paulo, v. 13, n. 3, set. 2010. Disponível em: <http://www.scielosp.org/scielo.php?script=sci_arttext\&pid=S1415-790X2010 000300014\&lng=pt\&nrm=iso>. http://dx.doi.org/10.1590/S1415-790X2010000300014; BERNARDES, Liliane Cristina Gonçalves; ARAUJO, Tereza Cristina Cavalcanti Ferreira. Deficiência, políticas públicas e bioética: percepção de gestores públicos e conselheiros de direitos. Ciência \& Saúde Coletiva, v. 17, n. 9, p. 2435-2445, 2012. Disponível em: <http://www.scielo.br/pdf/csc/v17n9/a24v17n9.pdf>. http:// dx.doi.org/10.1590/S1413-81232012000900024. BEVILACQUA, Gabriela; FARIAS, Mareni Rocha; BLATT, Carine Raquel. Aquisição de medicamentos genéricos em município de médio porte. Revista de Saúde Pública, São Paulo, v. 45, n. 3, June 2011. Disponível em: <http://www.scielo.br/scielo.php?script=sci_ arttext\&pid=S0034-89102011000300017\&Ing=en\&nrm=iso>. $\quad$ http://dx.doi.org/10.1590/S003489102011005000020. BOING, Alexandra Crispim et al. Desigualdade socioeconômica nos gastos catastróficos em saúde no Brasil. Revista de Saúde Pública, São Paulo, v. 48, n. 4, Aug. 2014. Disponível em: <http://www.scielo.br/scielo.php?script=sci_arttext\&pid=S0034-89102014000400632\&Ing=en\&nrm=iso>. http://dx.doi.org/10.1590/S0034-8910.2014048005111; BUSS, Paulo Marchiori; CARVALHO, Antonio Ivo de. Desenvolvimento da promoção da saúde no Brasil nos últimos vinte anos (1988-2008). Ciência \& Saúde Coletiva, Rio de Janeiro, v. 14, n. 6, Dec. 2009 Disponível em: <http://www.scielo.br/ scielo.php?script=sci_arttext\&pid=S1413-81232009000600039\&lng=en\&nrm=iso>. $\quad$ http://dx.doi. org/10.1590/S1413-81232009000600039. FERRAES, Alide Marina Biehl; CORDONI JUNIOR, Luiz. Consórcio de medicamentos no Paraná: análise de cobertura e custos. Revista de Administração Pública, v. 41, n. 3, p. 475-486, 2007. Disponível em: <http://www.scielo.br/pdf/rap/v41n3/a05v41n3.pdf>. http:// dx.doi.org/10.1590/S1020-49892003000300002; GRANGEIRO, A. et al. Sustentabilidade da política de acesso a medicamentos anti-retrovirais no Brasil. Revista de Saúde Pública, São Paulo, v. 40, p. 60-69, abr. 2006. Disponível em: <http://www.scielo.br/pdf/rsp/v40s0/09.pdf>. http://dx.doi.org/10.1590/ S0034-89102006000800009; GUERRA JR., Augusto A. et al. op. cit. LAGO, Regina Ferro do; COSTA, Nilson Rosário. Dilemas da política de distribuição de medicamentos antirretrovirais no Brasil. Ciência \& Saúde Coletiva, Rio de Janeiro, v. 15, n. 3, p. 3529-3540, nov. 2010. Disponível em: <http://www.scielo.br/pdf/ csc/v15s3/v15s3a28.pdf>. http://dx.doi.org/10.1590/S1413-81232010000900028; LEITE, Silvana.
} 
No âmbito dos estudos empíricos, os argumentos de ineficiência/desorganização do Estado restam muito claros, como depreendemos de diversos textos, dentre eles:

(a) Guerra destaca como resultados de seu estudo a disparidade entre a baixa disponibilidade de medicamentos essenciais nos setores públicos (almoxarifados municipais - 52\%; unidades públicas de saúde - 46,9\%; unidades ambulatoriais filantrópicas - $41 \%$; e unidades ambulatoriais privadas - $38,1 \%$ ) e a alta disponibilidade desses medicamentos nas farmácias privadas, que alcançou $81,2 \%{ }^{20}$.

(b) Diniz defende que os desafios quanto ao processo de aquisição e disponibilização de medicamentos podem se caracterizar como falhas da política, ou mesmo entraves à compreensão da política, para sua operacionalização nas diferentes esferas do poder público, levando o cidadão à busca de outras instâncias. Nesse sentido, a judicialização enquadra-se dentro do contexto da ausência de uma política clara do sistema de saúde ${ }^{21}$.

(c) Vieira obtém como conclusão que a maioria das demandas por medicamentos poderia ser evitada, caso as diretrizes do Sistema Único de Saúde (SUS) fossem cumpridas ${ }^{22}$. Também nesse sentido enquadram-se os artigos de Marques e Lopes ${ }^{23}$.

(d) Machado verificou que as evidências encontradas indicam que há casos em que houve falhas no sistema público de saúde, pois algumas demandas referiam-se a medicamentos constantes da lista do SUS que, por tal razão, deveriam estar disponíveis à população. Porém, considera que a solicitação judicial de medicamentos sem comprovação de eficácia e não padronizados pelo SUS constitui uma ratificação do uso irracional de recursos públicos e uma afronta às premissas da Política Nacional de Medicamentos ${ }^{24}$.

(e) Machado afirma que os resultados obtidos em seu estudo indicam que aproximadamente $5 \%$ dos medicamentos pleiteados não eram registrados na Agência

op. cit.; LOYOLA, Maria Andréa. Medicamentos e saúde pública em tempos de AIDS: metamorfoses de uma política dependente. Ciência \& Saúde Coletiva, Rio de Janeiro, v. 13, p. 763-778, jun. 2008. Disponível em: <http://www.scielo.br/pdf/csc/v13s0/a27v13s0.pdf>. http://dx.doi.org/10.1590/S141381232008000700027; MARQUES, Rosa Maria; MENDES, Áquila. Atenção Básica e Programa de Saúde da Família (PSF): novos rumos para a política de saúde e seu financiamento? Ciência \& Saúde Coletiva, São Paulo, v. 8, n. 2, p. 403-415, 2003. Disponível em: <http://www.scielo.br/pdf/csc/v8n2/a07v08n2.pdf>. http://dx.doi.org/10.1590/S1413-81232003000200007; VENTURA, Miriam et al. op. cit.; VILAS BÔAS, Ana Luiza Queiroz; PAIM, Jairnilson Silva. Práticas de planejamento e implementação de políticas no âmbito municipal." Cadernos de Saúde Pública 24, n. 5, p. 1239-1250, jun. 2008. Disponível em: <http://www. scielo.br/pdf/csp/v24n6/05.pdf>. http://dx.doi.org/10.1590/S0102-311X2008000600005.

${ }^{20}$ GUERRA JR, Augusto et al. op. cit.

${ }^{21}$ DINIZ, Debora; MEDEIROS, Marcelo; SCHWARTZ, Ida Vanessa. op. cit.

${ }^{22}$ VIEIRA, Fabiola; ZUCCHI, Paola. op. cit.

${ }^{23}$ MARQUES, Silvia; DALLARI, Sueli. op. cit. LOPES, Luciane. op. cit.

${ }^{24}$ MACHADO, Marina et al. op. cit. 
de Vigilância Sanitária (Anvisa); 19,6\% estavam presentes na Relação Nacional de Medicamentos Essenciais (Rename); 24,3\% compunham o Programa de Medicamentos de Alto Custo; e 53,9\% apresentavam evidência consistente de eficácia. Dentre os medicamentos não disponíveis no sistema público, $79 \%$ apresentavam alternativa terapêutica nos programas de assistência farmacêutica. A conclusão proposta é que há falhas do sistema público de saúde, uma vez que há solicitações de medicamentos constantes de suas listas ${ }^{25}$.

(f) Pepe sugere que, além de problemas relacionados à aquisição, distribuição e dispensação de itens listados, os medicamentos não selecionados em listas oficiais foram também grande motivação da demanda ${ }^{26}$. E

(g) Macedo aponta que, dos medicamentos solicitados, 14,3\% deveriam estar disponíveis na atenção básica do SUS; 19,5\%, no componente de medicamentos de dispensação excepcional; e 66,2\% não pertenciam a nenhuma lista oficial. Conclui que a via judicial tem sido utilizada para garantir tanto o acesso a medicamentos cujo fornecimento está previsto pelo SUS como a medicamentos não incorporados por ele, e reforça a necessidade de análise técnica para a tomada de decisão sobre o fornecimento de medicamentos, ainda que pela via judicial ${ }^{27}$.

Um segundo ponto de destaque nos dados obtidos nas pesquisas refere-se à falta de entendimento entre os poderes, em especial a não consideração, nas decisões judiciais amplamente concessivas de medidas não previstas nas políticas públicas voltadas à saúde, das normas emitidas pelos legisladores e pelos gestores públicos. Neste sentido:

(a) Machado considera que a solicitação judicial por medicamentos sem comprovação de eficácia e não padronizados pelo SUS constitui uma ratificação do uso irracional de recursos públicos e uma afronta às premissas da Política Nacional de Medicamentos ${ }^{28}$.

(b) Baptista conclui pela desarticulação entre os poderes e diversas deficiências legislativas e da administração pública na elaboração e execução das políticas voltadas à área da saúde, acarretando a ampliação do papel do Poder Judiciário não só no atendimento pontual da demanda, mas também na responsabilização do Estado de desenvolver procedimentos de atendimento de saúde adequados pela rede pública, com destaque para incorporação, compra e dispensação de medicamentos ${ }^{29}$.

\footnotetext{
${ }^{25}$ MACHADO, Marina et al. op. cit.

${ }^{26}$ PEPE, Vera Lúcia E. et al. A judicialização da saúde e os novos desafios da gestão da assistência farmacêutica, cit.

${ }^{27}$ MACEDO, Eloisa; LOPES, Luciane; BARBERATO-FILHO, Silvio. op. cit.

${ }^{28}$ MACHADO, Marina et al. op. cit.

${ }^{29}$ BAPTISTA, Tatiana; MACHADO, Cristiani; LIMA, Luciana. op. cit.
} 
(c) Barbosa destaca a desarticulação entre as decisões judiciais emitidas pelo Supremo Tribunal Federal (STF) sobre a dispensação de medicamentos para o tratamento da AIDS e as políticas públicas de saúde elaboradas pelo Governo Federal, por meio dos poderes Executivo e Legislativo. Conclui seu texto com a afirmação de que as decisões judiciais, especialmente as do STF, devem considerar em seus fundamentos a limitação orçamentária e a organização das políticas públicas, sob pena de levar à incapacidade gerencial dos órgãos públicos e, consequentemente, à ineficácia dos programas governamentais ${ }^{30}$.

(d) Borges defende que as decisões judiciais concedem os pedidos de fornecimento de medicamentos sem que se pondere a padronização de medicamentos adotada pelo Ministério da Saúde, considerando, portanto, a intervenção judicial como excessiva ${ }^{31}$.

(e) Leite afirma que o fornecimento de medicamentos por compra direta não está adequadamente inserido na gestão da assistência farmacêutica municipal, desrespeitando a Política Nacional de Medicamentos. O fornecimento de medicamentos não vinculado a uma organização da assistência farmacêutica municipal não só pela judicialização, mas também pelo atendimento de demandas individuais por meio da assistência social (inclusive "terceirizado" por uma organização social) - compromete a consolidação de propostas como a referida acima ${ }^{32}$.

(f) Messeder sugere demora no julgamento das ações, cuja maioria é conduzida pela defensoria pública para usuários do SUS. Notou-se a oficialização de práticas prescritivas, com a inclusão de medicamentos frequentemente solicitados nas listas de financiamento público, dificultando adesão ao uso racional de medicamentos. Medicamentos cuja competência de fornecimento é dos municípios são solicitados ao Estado, que, por sua vez, falha no repasse. A aparente falta de esclarecimento dos autores e condutores das ações gera desgaste na relação Executivo-Judiciário e desvio dos recursos para ações coletivas de assistência farmacêutica ${ }^{33}$.

(g) Borges propõe que o Judiciário busque critérios para racionalizar e uniformizar sua atuação, de forma a superar os obstáculos, por meio de sua aproximação com os órgãos do Poder Executivo e da verificação da padronização dos medicamentos pleiteados pelo MS e se o médico prescritor e o receituário são do SUS. Ademais, entende que os conflitos não devem se tornar uma busca individualizada pela efetivação de políticas públicas, como vem ocorrendo no caso do fornecimento de medicamentos ${ }^{34}$.

\footnotetext{
${ }^{30}$ BARBOSA, Mariana. op. cit.

${ }^{31}$ BORGES, Danielle da C. L.; UGÁ, Maria Alicia D. Conflitos e impasses da judicialização na obtenção de medicamentos: as decisões de $1^{\mathrm{a}}$ instância nas ações individuais contra o Estado do Rio de Janeiro, Brasil, em 2005, cit.

${ }^{32}$ LEITE, Silvana et al. op. cit.

${ }^{33}$ MESSENDER, Ana Márcia; OSORIO-DE-CASTRO, Claudia; LUIZA, Vera. op. cit.

${ }^{34}$ BORGES, Danielle da C. L.; UGÁ, Maria Alicia D. As ações individuais para o fornecimento de medicamentos no âmbito do SUS: características dos conflitos e limites para a atuação judicial, cit.
} 
(h) Vieira levanta que os serviços do SUS originaram 59\% das prescrições (26\% municipais e 33\% dos demais). Câncer e diabetes foram as doenças mais referidas (59\%). Faziam parte de listas de serviços 62\% dos medicamentos solicitados. O gasto total foi de $\mathrm{R} \$ 876$ mil, efetuado somente para itens não selecionados (que não fazem parte da Rename); $73 \%$ dos quais poderiam ser substituídos. Do gasto total, $75 \%$ foram destinados à aquisição de antineoplásicos, cuja comprovação de eficácia necessita de mais ensaios clínicos. Ao final, defende que a maioria das demandas por medicamentos geradas por ações judiciais poderia ser evitada se fossem consideradas as diretrizes do SUS, a organização do atendimento em oncologia e a observância das relações de medicamentos essenciais. A falta dessa observância compromete a Política Nacional de Medicamentos, a equidade no acesso e o uso racional de medicamentos no SUS $^{35}$.

Outro ponto frequentemente abordado quanto ao tema judicialização da saúde refere-se aos limites orçamentários para o atendimento de toda e qualquer demanda, sendo citada em diversas oportunidades a expressão "escassez de recursos". Dentro desse contexto, destaca-se que:

(a) Barbosa considera fundamental que, ao decidir pela realização dos direitos sociais, o STF sopese a limitação orçamentária e as políticas públicas, sob pena de ocasionar a incapacidade gerencial das instituições públicas e a ineficácia dos programas de ação governamental, retrocedendo na proteção e efetivação dos direitos assegurados na Constituição Federal. Mas suas próprias evidências já demonstram que $58,3 \%$ das decisões analisadas consideraram algum critério econômico, contra $41,7 \%$ que não abordaram o aspecto financeiro da concessão de medicamentos ${ }^{36}$.

(b) Ferraz traz em seu artigo as noções de complexidade técnica das demandas na área de saúde e de escassez de recursos, a qual demanda a identificação de prioridades e a implementação de escolhas por parte dos gestores públicos. Considera, por fim, que a judicialização acarreta uma inversão dos objetivos primordiais do SUS, pois entende que o acesso efetivo ao Judiciário no Brasil é facilitado às pessoas de condições socioeconômicas mais avantajadas ${ }^{37}$.

(c) Mazza considera que o STF geralmente não leva em consideração as regras e o planejamento orçamentários quando das suas decisões no campo de saúde. É necessário haver equilíbrio e proporcionalidade nas decisões do Poder Judiciário que envolvam o direito à saúde, pois a saúde e o orçamento convivem lado a lado ${ }^{38}$.

(d) Vieira argumenta que a escassez de recursos requer a formulação de políticas para alocação compatível com os princípios de universalidade, integralidade,

\footnotetext{
${ }^{35}$ VIEIRA, Fabiola; ZUCCHI, Paola. op. cit.

${ }^{36}$ BARBOSA, Mariana.op. cit. MAZZA, Fabio.op. cit.

${ }^{37}$ FERRAZ, Octávio; VIEIRA, Fabiola.op. cit.

${ }^{38}$ MAZZA, Fabio.op. cit.
} 
igualdade e equidade do SUS, e que é necessária a discussão sobre o impacto das ações judiciais de medicamentos não ofertados pelo sistema e o comportamento do Judiciário brasileiro em relação a elas ${ }^{39}$.

Utilizando a consideração orçamentária, mas em sentido contrário aos demais, Cardoso cita algumas decisões do STF, entre elas a de que a mera alegação de insuficiência orçamentária, sem a devida e indiscutível comprovação, não pode ser aceita com esse intuito (AgRg-RE n. 271286/RS ${ }^{40}$; ADPF n. $45^{41}$ ). Conclusivamente, destaca: (a) a omissão reiterada do Legislativo brasileiro na concretização dos direitos fundamentais; (b) a igual inércia do Executivo, e suas questionáveis "escolhas trágicas", tais como a aquisição de 15 milhões de embalagens sachê de gel lubrificante (no valor aproximado de $\mathrm{R} \$ 40$ milhões) e mais de um bilhão de preservativos, às vésperas do Carnaval, em detrimento do fornecimento de outros medicamentos ou tratamentos; (c) a substituição, pelo Judiciário, de uma função que seria do Executivo; (d) a legitimidade - ou não - do processo judicial como uma forma democrática de se decidir sobre a concessão de um remédio ou de um tratamento médico a determinada pessoa; (e) a limitação orçamentária para implementação de políticas públicas como medida para a efetivação dos direitos, importando na necessidade das "escolhas trágicas" e levando ao argumento da reserva do possível como razoável para afastar o fornecimento de medicamentos pelo Executivo; e (f) o dever da família, sociedade e Estado na garantia da saúde ${ }^{42}$.

Outro fator utilizado como argumento, em muito relacionado à questão financeira das demandas, refere-se ao binômio coletivo/individual. Para alguns autores, o atendimento das demandas individuais prejudicaria a alocação dos mesmos recursos em atendimento às políticas públicas voltadas à coletividade. São exemplos:

(a) Andrade afirma que, em uma primeira análise superficial, pode-se inferir que a via judicial tem propiciado o exercício dos princípios constitucionais de universalidade, integralidade e equidade na assistência à saúde. Porém, quando se analisa de forma mais ampla, percebe-se uma lógica adversa: se, por um lado, as decisões judiciais visam a garantir o atendimento ao direito e às necessidades do cidadão, por outro, remetem ao gestor a responsabilidade de decisões administrativas que muitas vezes contradizem os princípios constitucionais de equidade e acesso igualitário à assistência à saúde de qualidade ${ }^{43}$.

\footnotetext{
${ }^{39}$ VIEIRA, Fabiola.op. cit. BARBOSA, Mariana. op. cit.

${ }^{40}$ BRASIL. Supremo Tribunal Federal. Arguição de Descumprimento de Preceito Fundamental n. 45. Disponivel em: <http://www.stf.jus.br/portal/processo/verProcessoAndamento.asp?incidente=1820623>. Acesso em: 17 set. 2015.

${ }^{41}$ BRASIL. Supremo Tribunal Federal. Recurso Extraordinário n. 271286. Disponível em: <http://www.stf.jus. $\mathrm{br} /$ portal/processo/verProcessoAndamento.asp?incidente=2175381>. Acesso em: 17 set. 2015.

${ }^{42}$ CARDOSO, Oscar.op. cit.

${ }^{43}$ ANDRADE, Eli et al.op. cit.
} 
(b) Tanaka conclui que o desafio do SUS está entre garantir o fundamental para toda a população brasileira e atender ao direito individual à saúde de alguns poucos indivíduos que conseguem, por meio de uma decisão judicial, a dispensação de medicamentos cujos custo e efetividade não são plenamente conhecidos e validados, como acontece na disponibilização pelo SUS ${ }^{44}$. E

(c) Marques observou que, em 96,4\% dos casos analisados, houve a condenação do Estado a fornecer o medicamento nos exatos moldes do pedido do autor, inclusive quando o medicamento não possuía registro na Anvisa (9,6\% dos casos analisados); $100 \%$ dos processos eram individuais; em $77,4 \%$ a requisição foi específica em relação ao laboratório farmacêutico; e, em 93,5\% dos casos, os medicamentos foram concedidos judicialmente ao autor em caráter de urgência, por meio de medida liminar. No entender do autor, a judicialização prejudica a tomada de decisões coletivas pelo sistema político, pois as decisões judiciais não tomam conhecimento dos elementos constantes na política pública de medicamentos, editada conforme o direito para dar concretude ao direito social à assistência farmacêutica ${ }^{45}$.

A última tese a ser destacada é a de que a judicialização é um movimento das elites econômicas brasileiras, pois os que têm acesso ao Poder Judiciário são os cidadãos com poder aquisitivo e com formação educacional - e por vezes, aparece a menção ao financiamento dessas demandas por parte de empresas de medicamentos.

(a) Chieffi obtém como resultados em relação ao local de prescrição: $48 \%$ dos pacientes possuíam receitas médicas de estabelecimentos da rede do SUS; $47 \%$, do sistema complementar; e, em $4 \%$ dos atendimentos, não foi possível classificar a origem da receita. A maioria das ações analisadas foi ajuizada por advogados particulares, sendo que a justiça gratuita contribuiu tão somente com um quarto das ações. O fato de essas ações geralmente serem ajuizadas por advogados particulares, segundo o autor, demonstra que os pacientes arcaram com os custos dessa representação e, em princípio, poderiam adquirir os medicamentos solicitados. Comparando a frequência acumulada, verificou seu estudo que: aproximadamente $74 \%$ dos pacientes residem em áreas pertencentes aos estratos 1,2 e 3; já na população em geral, essa porcentagem é de 53\%. Considerando apenas os estratos $1 \mathrm{e}$ 2, os mais bem aquinhoados da população, a parcela atendida pelas ações judiciais é o dobro de sua distribuição na população geral. Como conclusão, defende que a parcela da população atendida por demandas judiciais tem, em média, melhores condições socioeconômicas, residindo em áreas com baixa ou sem nenhuma vulnerabilidade social ${ }^{46}$.

\footnotetext{
${ }^{44}$ TANAKA, Oswaldo.op. cit.

${ }^{45}$ MARQUES, Silvia; DALLARI, Sueli.op. cit.

${ }^{46} \mathrm{CHIEFFI}$, Ana Luiza; BARATA, Rita B. Judicialização da política pública de assistência farmacêutica e equidade, cit.
} 
(b) O mesmo autor, em um segundo artigo, traz como evidência que os medicamentos solicitados nas demandas judiciais analisadas foram prescritos por 878 médicos diferentes e que 35\% das ações foram apresentadas por $1 \%$ dos advogados. Orientados pelos próprios médicos ou por associações de portadores da patologia, frequentemente subsidiadas pelas indústrias farmacêuticas, os pacientes procuram a via judicial para obter a garantia de acesso. O processo se repete, ampliando progressivamente o número de demandantes. A observação de que mais de $70 \%$ das ações ajuizadas para certos medicamentos são de responsabilidade de um advogado leva à conclusão é possível sugerir uma relação estreita entre o advogado e o fabricante do medicamento ${ }^{47}$.

(c) Machado afirma que cerca de $70 \%$ dos autores foram atendidos no sistema privado de saúde e $60,3 \%$ foram representados por advogados particulares. Esses resultados sugeririam, em sua visão, que os pacientes que recorrem ao Poder Judiciário talvez tenham melhores condições socioeconômicas, considerando que podem arcar com as despesas processuais e ter maior conhecimento de seus direitos, podendo agravar a iniquidade no acesso à saúde de um sistema já marcado por desigualdades socioeconômicas ${ }^{48}$. E

(d) Campos levanta que, em sua pesquisa, houve predomínio de representação por advogados particulares e atendimento por médicos do setor privado. Entre as ações representadas pelo escritório A, 43,6\% tiveram um único médico prescritor e 29 médicos foram responsáveis por 40,2\% dos pedidos do mesmo fármaco. Apenas um médico foi responsável por 16,5\% das prescrições de um dos medicamentos, solicitado por apenas um escritório particular de advocacia, em 44,8\% dos pedidos. A conclusão é de que a maior representatividade de médicos do setor privado e advogados particulares pode trazer prejuízo à equidade, entendendo que os dados sugerem associação entre médicos e escritórios de advocacia nas solicitações dos medicamentos. Vê ainda indícios de que a Justiça e a medicina têm sido utilizadas para atender aos interesses da indústria farmacêutica ${ }^{49}$.

\section{Considerações finais}

Algumas das teses defendidas no debate nacional não se sustentam com os dados apresentados, sendo inclusive verificável a defesa de argumentos opostos com base nas mesmas pesquisas. É o caso da afirmação de escassez de recursos e limitação orçamentária. Os dados obtidos demonstram, sim, custos altos com diversas demandas, em especial as relativas à aquisição de medicamentos. Entretanto, desse resultado não é possível afirmar que o Estado brasileiro não possui recursos

\footnotetext{
${ }^{47}$ CHIEFFI, Ana Luiza; BARATA, Rita de Cássia B. Ações judiciais: estratégia da indústria farmacêutica para introdução de novos medicamentos, cit.

${ }^{48}$ MACHADO, Marina et al. op. cit.

${ }^{49}$ CAMPOS NETO, Orozimbo et al. op. cit.
} 
suficientes para atender a essas demandas. Ademais, sem que seja feita uma discussão sobre o montante que a sociedade brasileira entende como justo e recomendável para as demandas de saúde, não será possível a discussão sobre priorização nessa área. Ratifica-se que a afirmação de que não será possível atender a toda e qualquer demanda não qualifica o debate sobre o atendimento das necessidades de saúde.

Nesse mesmo sentido, critica-se a argumentação que coloca como conflitantes os direitos coletivo e individual. $\mathrm{O}$ atendimento de uma demanda individual não necessariamente leva à desconsideração da coletividade. Afinal, o coletivo é feito de indivíduos. Mais uma vez, desloca-se para a discussão maior sobre a necessidade de justificação, transparência e democracia quando das decisões de alocação de recursos para um aspecto pontual de atendimento de uma demanda.

Por fim, quanto à tese de ser a judicialização um movimento das elites econômicas brasileiras, ela parece apresentar três dificuldades. Primeiro, há pesquisas em sentido inverso, inclusive citadas neste texto, que apontam para uma participação representativa de instituições públicas de defesa dos demandantes e também para uma maior cidadania, por meio do próprio processo de judicialização. Ademais, os dados apresentados têm caráter local, não podendo ser generalizados para a realidade complexa da sociedade brasileira. Por fim, o direito à saúde é universal e, assim, deve ser assegurado a todos os cidadãos, independentemente de sua classe econômica. Alegar que a população financeiramente mais abastada tem acesso ao direito à saúde por meio do Poder Judiciário não é, por si só, suficiente para justificar seu cabimento ou não.

Pela Teoria de Justiça de Daniels voltada às questões de saúde, apreende-se que o debate brasileiro não tem muitos conflitos quanto à importância moral especial do tema. Mesmo sem que seja feita uma reflexão teórica e filosófica ampla sobre a questão moral do direito à saúde, tanto a legislação, como a literatura preservam a importância de tais direitos, revelando que o primeiro aspecto da teoria de Daniels é atendido. Nota-se ainda que há ausência do segundo aspecto da teoria, que se refere à reflexão de quando uma desigualdade de saúde pode ser considerada injusta. Tais reflexões não foram observadas nos documentos analisados. Considera-se esta a primeira contribuição do autor quando relacionado ao debate nacional. Centrar a discussão sobre judicialização à saúde em elementos meramente orçamentários ou de acesso ao direito por determinada classe social restringe enormemente as considerações éticas que devem ser feitas. O direito e o acesso à saúde são elementos que devem ser inseridos dentro da análise das políticas sociais de forma geral. Ao verificar a crescente demanda judicial por serviços e bens relacionados à saúde, a bibliografia brasileira apresenta uma problemática social que não deve ser afastada por diagnósticos pontuais, direcionados apenas por questões de limitação orçamentária. A busca por atendimento das necessidades de saúde, por meio de qualquer um dos três poderes, demanda uma reflexão sobre quais políticas públicas devem ser repensadas ou mais bem acompanhadas. 
A segunda contribuição de Daniels que deve ser assimilada pelo debate nacional é a premência de o Brasil discutir o terceiro elemento de sua teoria: como podemos atender às necessidades de saúde se não conseguimos atender a todas as necessidades. Diante da literatura nacional, percebe-se que o debate brasileiro é centrado na desorganização do Estado, seja pela ausência ou inadequação das normas editadas pelo Poder Executivo, seja pela incompatibilidade das leis com as normas expedidas por ele, seja pela ineficiência na implementação das políticas públicas já aprovadas. Todos esses fatores reunidos levam à necessidade de atuação do Poder Judiciário. Porém, mesmo havendo certo consenso sobre a necessidade de tal atuação, também é referida como desorganização do Estado a ausência de regras que estabeleçam limites e critérios para a decisão judicial, muitas vezes acarretando a piora no quadro de desordem na concretização do direito à saúde.

Cabe neste momento voltar o debate sobre os procedimentos necessários para reverter tal quadro de desorganização, levando à reflexão sobre como podemos priorizar as necessidades encontradas em nossa sociedade. Os procedimentos devem ser democráticos, transparentes e dialógicos, e sua forma de implementação para que as escolhas feitas por todos os poderes - Executivo, por meio de suas políticas públicas; Legislativos, pela edição de normas; e Judiciário, por meio das decisões judiciais - atendam às prioridades estabelecidas por esses procedimentos. Nesse sentido, Daniels propõe que muito se avançaria para resolver os problemas de falta de legitimidade e injustiças na área de saúde se as decisões públicas quanto à fixação de limites e à disponibilização ou não de determinado bem ou serviço fosse pautada não apenas na argumentação de custo, mas também em argumentações que demonstrassem que essa limitação se encaixa dentro de uma política pública formulada de modo a satisfazer, da melhor forma possível, as necessidades saúde de sua população sob condições reais e razoáveis de restrições de recursos.

\section{Referências}

ACURCIO, Francisco de Assis; GUIMARÃES, Mark Drew Crosland. Acessibilidade de indivíduos infectados pelo HIV aos serviços de saúde: uma revisão de literatura. Cadernos de Saúde Pública, São Paulo, v. 12, n. 2, jun. 1996. Disponível em: <http://www.scielo.br/scielo. php?script=sci_arttext\&pid=S0102-311X1996000200012\&lng=en\&nrm=iso $>$. Acesso em: 10 fev. 2014. http://dx.doi.org/10.1590/S0102-311X1996000200012.

ANDRADE, Eli I. G. et al. A judicialização da saúde e a Política Nacional de Assistência Farmacêutica no Brasil: gestão da clínica e medicalização da justiça. Revista Médica de Minas Gerais, v. 18, n. 4, supl. 4, p. S46-S50, 2008. Disponível em: <http://rmmg.org/artigo/ detalhes/1268>. Acesso em: 25 set. 2015.

APPIO, Eduardo. A judicialização da política em Dworkin. Revista Seqüência, n. 47, p. 81-97, dez. 2003. 
ASENSI, Felipe D. Judicialização ou juridicização? As instituições jurídicas e suas estratégias na saúde. Physis: Revista de Saúde Coletiva, Rio de Janeiro, v.20, n. 1, p. 33-55, 2010. Disponível em: <http://www.scielo.br/pdf/physis/v20n1/a04v20n1.pdf>. http://dx.doi.org/10.1590/S0103-73312010000100004.

BAHIA, Ligia; COSTA, Nilson Rosário; STRALEN, Cornelis Van. A saúde na agenda pública: convergências e lacunas nas pautas de debate e programas de trabalho das instituições governamentais e movimentos sociais. Ciência \& Saúde Coletiva, v. 12, p. 1791-1818, 2007. Disponível em: <http://www.scielo.br/pdf/csc/v12s0/04.pdf>. http://dx.doi.org/10.1590/S1413-81232007000700004.

BAPTISTA, Tatiana W. de F.; MACHADO, Cristiani V.; LIMA, Luciana D. de. Responsabilidade do Estado e direito à saúde no Brasil: um balanço da atuação dos Poderes. Ciência \& Saúde Coletiva, v. 14, n. 3, p. 829-839, 2009. Disponível em: <http://www.scielo.br/pdf/csc/v14n3/18. pdf> http://dx.doi.org/10.1590/S1413-81232009000300018.

BARBOSA, Mariana G. O STF e a política de fornecimento de medicamentos para tratamento da AIDS/HIV. Revista Jurídica, v. 9, n. 88, 2007. Disponível em: <http://www.planalto.gov. br/ccivil_03/revista/Rev_88/MonoDisTeses/MarianaBarbosa.pdf>. Acesso em: 25 set. 2015.

BARROSO, Luís R. Da falta de efetividade à judicialização excessiva: direito à saúde, fornecimento gratuito de medicamentos e parâmetros para a atuação judicial. Revista da Procuradoria-Geral do Estado do Rio Grande do Sul, Porto Alegre, v. 31, n. 66, p. 89-114, 2007.

BERNARDES, Liliane Cristina Gonçalves; ARAUJO, Tereza Cristina Cavalcanti Ferreira. Deficiência, políticas públicas e bioética: percepção de gestores públicos e conselheiros de direitos. Ciência \& Saúde Coletiva, v. 17, n. 9, p. 2435-2445, 2012. Disponível em: <http://www.scielo.br/pdf/csc/v17n9/a24v17n9.pdf>. http://dx.doi.org/10.1590/S1413-81232012000900024.

BERSUSA, Ana Aparecida Sanches et al. Acesso a serviços de saúde na Baixada Santista de pessoas portadoras de hipertensão arterial e ou diabetes. Revista Brasileira de Epidemiologia, São Paulo, v. 13, n. 3, set. 2010. Disponível em: <http://www.scielosp. org/scielo.php?script=sci_arttext\&pid=S1415-790X2010000300014\&lng=pt\&nrm=iso $>$. http://dx.doi.org/10.1590/S1415-790X2010000300014.

BEVILACQUA, Gabriela; FARIAS, Mareni Rocha; BLATT, Carine Raquel. Aquisição de medicamentos genéricos em município de médio porte. Revista de Saúde Pública, São Paulo, v. 45, n. 3, June 2011. Disponível em: <http://www.scielo.br/scielo. php? script $=$ sci_arttext $\&$ pid $=S 0034-89102011000300017 \& \operatorname{lng}=$ en $\&$ nrm $=$ iso $>$. http://dx.doi.org/10.1590/S0034-89102011005000020.

BOING, Alexandra Crispim et al. Desigualdade socioeconômica nos gastos catastróficos em saúde no Brasil. Revista de Saúde Pública, São Paulo, v. 48, n. 4, Aug. 2014. Disponível em: $<$ http://www.scielo.br/scielo.php?script=sci_arttext\&pid=S0034-89102014000400632\&ln $\mathrm{g}=\mathrm{en} \& \mathrm{nrm}=\mathrm{iso}>$. http://dx.doi.org/10.1590/S0034-8910.2014048005111. 
BORGES, Danielle da C. L.; UGÁ, Maria Alicia D. As ações individuais para o fornecimento de medicamentos no âmbito do SUS: características dos conflitos e limites para a atuação judicial. Revista de Direito Sanitário, v. 10, n. 1, p. 13-38, 2009. Disponível em: <http://www.revistas. usp.br/rdisan/article/view/13144>. http://dx.doi.org/10.11606/issn.2316-9044.v10i1p13-38.

decisões de $1^{\text {a }}$ instância nas ações individuais contra o Estado do Rio de Janeiro, Brasil, em 2005. Cadernos de Saúde Pública, São Paulo, v. 26, n. 1, p. 59-69, 2010. Disponível em: <http:// www.scielo.br/pdf/csp/v26n1/07.pdf>. http://dx.doi.org/10.1590/S0102-311X2010000100007.

BUSS, Paulo Marchiori; CARVALHO, Antonio Ivo de. Desenvolvimento da promoção da saúde no Brasil nos últimos vinte anos (1988-2008). Ciência \& Saúde Coletiva, Rio de Janeiro, v. 14, n. 6, Dec. 2009 Disponível em: <http://www.scielo.br/scielo. php? script $=$ sci_arttext $\&$ pid $=S 1413-81232009000600039 \& \operatorname{lng}=$ en $\& \mathrm{nrm}=\mathrm{iso}>$. http://dx.doi.org/10.1590/S1413-81232009000600039.

CAMPOS, Célia Maria Sivalli; BATAIERO, Marcel Oliveira. Necessidades de saúde: uma análise da produção científica brasileira de 1990 a 2004. Interface - Comunicação, Saúde, Educação, v. 11, n. 23, p. 605-618, set./dez. 2007. Disponível em: <http://www.scielo.br/pdf/ icse/v11n23/a14v1123.pdf>. http://dx.doi.org/10.1590/S1414-32832007000300014.

CAMPOS NETO, Orozimbo H. et al. Médicos, advogados e indústria farmacêutica na judicialização da saúde em Minas Gerais, Brasil. Revista de Saúde Pública, v.46, n. 5, p. 784-790, 2012. Disponível em: <http://www.scielo.br/pdf/rsp/v46n5/04.pdf>. http://dx.doi.org/10.1590/S0034-89102012000500004.

CARDOSO, Oscar V. Questões controversas sobre a determinação judicial de fornecimento de medicamentos excepcionais pelo poder público. Revista CEJ - Centro de Estudos Judiciários do Conselho da Justiça Federal, v.13, n. 45, p. 46-55, 2009.

CARLINI, Angélica L. Judicialização da saúde pública no Brasil: causas e possibilidades. 2011. Tese (Doutorado) - Universidade Presbiteriana Mackenzie, São Paulo, 2011.

CHAVES, Gabriela C. et al. A evolução do sistema internacional de propriedade intelectual: proteção patentária para o setor farmacêutico e acesso a medicamentos. Cadernos de Saúde Pública, v.23, n. 2, p. 257-267, 2007. Disponível em: <http://www.scielo.br/pdf/csp/v23n2/02. pdf>. http://dx.doi.org/10.1590/S0102-311X2007000200002.

; VIEIRA, Marcela F.; REIS, Renata. Acesso a medicamentos e propriedade intelectual no Brasil: reflexões e estratégias da sociedade civil. Sur: revista internacional de direitos humanos, v. 5, n. 8, p. 170-198, 2008. Disponível em: <http://www.scielo.br/pdf/sur/v5n8/ v5n8a09.pdf>. http://dx.doi.org/10.1590/S1806-64452008000100009.

CHIEFFI, Ana Luiza; BARATA, Rita B. Judicialização da política pública de assistência farmacêutica e eqüidade. Cadernos de Saúde Pública, v. 25, n. 8, p. 1839-1849, 2009. Disponível em: <http://www.scielo.br/pdf/csp/v25n8/20.pdf>. http://dx.doi.org/10.1590/S0102-311X2009000800020. 
CHIEFFI, Ana Luiza; BARATA, Rita B. Ações judiciais: estratégia da indústria farmacêutica para introdução de novos medicamentos. Revista de Saúde Pública, São Paulo, v. 44, n. 3, p. 421-429, 2010. Disponível em: <http://www.scielo.br/pdf/rsp/v44n3/05.pdf>. http://dx.doi.org/10.1590/S0034-89102010000300005.

COSTA-COUTO, Maria Helena; NASCIMENTO, Álvaro C. Assimetria nas relações internacionais, propriedade industrial e medicamentos anti-aids. Ciência \& Saúde Coletiva, v. 13, n. 6, p. 1869-1877, 2008. Disponível em: <http://www.scielo.br/pdf/csc/v13n6/a22v13n6. pdf >. http://dx.doi.org/10.1590/S1413-81232008000600022.

DALLARI, Sueli G. Controle judicial da política de assistência farmacêutica: direito, ciência e técnica. Physis: revista de saúde coletiva, v. 20, n. 1, p. 57-75, 2010. Disponível em: <http://www.scielo.br/pdf/physis/v20n1/a05v20n1.pdf>. http://dx.doi.org/10.1590/S0103-73312010000100005.

DANIELS, Norman. Just health: meeting health needs fairly. Cambridge: Cambridge University Press, 2008.

; SABIN, James. Limits to health care: fair procedures, democratic deliberation, and the legitimacy problem for insurers. Philosophy \& Public Affairs, v. 16, n. 4, p. 303-350, 1997), p. 303-350. Disponível em: <http://www.jstor.org/stable/2961905accessed:22-04-2015>. 10.1111/j.1088-4963.1997.tb00082.x.

DINIZ, Debora; MEDEIROS, Marcelo; SCHWARTZ, Ida Vanessa D. Consequências da judicialização das políticas de saúde: custos de medicamentos para as mucopolissacaridoses. Cadernos de Saúde Pública, v.28, n. 3, p. 479-489, 2012. Disponível em: <http://www.scielo. br/pdf/csp/v28n3/08.pdf>. http://dx.doi.org/10.1590/S0102-311X2012000300008.

ENGELMANN, Fabiano; CUNHA FILHO, Marcio C. Ações judiciais, conteúdos políticos: uma proposta de análise para o caso brasileiro. Revista de Sociologia e Política, v.21, n. 45, p. 57-72, 2013.

FARIAS, Andrezza Duarte et al. Indicadores de prescrição médica nas unidades básicas de Saúde da Família no município de Campina Grande, PB. Revista Brasileira de Epidemiologia, São Paulo, v. 10, n. 2, p. 149-156, Jun. 2007. Disponível em: <http://www.scielo.br/pdf/rbepid/ v10n2/02.pdf>. http://dx.doi.org/10.1590/S1415-790X2007000200003.

FERRAES, Alide Marina Biehl; CORDONI JUNIOR, Luiz. Consórcio de medicamentos no Paraná: análise de cobertura e custos. Revista de Administração Pública, v. 41, n. 3, p. 475-486, 2007. Disponível em: <http://www.scielo.br/pdf/rap/v41n3/a05v41n3.pdf>. http://dx.doi. org/10.1590/S1020-49892003000300002.

FERRAZ, Octávio L. M.; VIEIRA, Fabiola S. Direito à saúde, recursos escassos e equidade: os riscos da interpretação judicial dominante. Dados: revista de ciências sociais, v.52, n. 1, p. 223-251, 2009. Disponível em: <http://www.scielo.br/pdf/dados/v52n1/v52n1a07.pdf>. http://dx.doi.org/10.1590/S0011-52582009000100007. 
FIGUEIREDO, Tatiana; PEPE, Vera Lúcia E.; OSORIO-DE-CASTO, Claudia G. S. Um enfoque sanitário sobre a demanda judicial de medicamentos. Physis: revista de saúde coletiva, v. 20, n. 1, p. 101-118, 2010. Disponível em: <http://www.scielo.br/pdf/physis/v20n1/a07v20n1. pdf>. http://dx.doi.org/10.1590/S0103-73312010000100007.

GRANGEIRO, A. et al. Sustentabilidade da política de acesso a medicamentos anti-retrovirais no Brasil. Revista de Saúde Pública, São Paulo, v. 40, p. 60-69, abr. 2006. Disponível em: <http:// www.scielo.br/pdf/rsp/v40s0/09.pdf>. http://dx.doi.org/10.1590/S0034-89102006000800009.

GUERRA JR., Augusto A. et al. Disponibilidade de medicamentos essenciais em duas regiões de Minas Gerais, Brasil. Revista Panamericana de Salud Pública, Washington, v. 15, n. 3, p. 168-175, mar. 2004. Disponível em: <http://www.scielosp.org/pdf/rpsp/v15n3/a05v15n3. pdf>. http://dx.doi.org/10.1590/S1020-49892004000300005.

HAYDEN, Cori. Sem patente não há genérico: acesso farmacêutico e políticas de cópia. Sociologias, n. 19, p. 62-91, 2008. Disponível em: <http://seer.ufrgs.br/index.php/sociologias/ article/view/5668/3266>. Acesso em: 25 set. 2015.

JANNUZZI, Anna H. L.; VASCONCELLOS, Alexandre G.; SOUZA, Cristina G. de. Especificidades do patenteamento no setor farmacêutico: modalidades e aspectos da proteção intelectual. Cadernos de Saúde Pública, v. 24, n. 6, p. 1205-1218, 2008.

LAGO, Regina Ferro do; COSTA, Nilson Rosário. Dilemas da política de distribuição de medicamentos antirretrovirais no Brasil. Ciência \& Saúde Coletiva, Rio de Janeiro, v. 15, n. 3 , p. 3529-3540, nov. 2010. Disponível em: <http://www.scielo.br/pdf/csc/v15s3/v15s3a28.pdf>. http://dx.doi.org/10.1590/S1413-81232010000900028.

LEITE, Silvana N. et al. Ações judiciais e demandas administrativas na garantia do direito de acesso a medicamentos em Florianópolis-SC. Revista de Direito Sanitário, v. 10, n. 2, p. 13-28, 2009. Disponível em: <http://www.revistas.usp.br/rdisan/article/view/13161>. http://dx.doi.org/10.11606/issn.2316-9044.v10i2p13-28.

; MAFRA, Ana Cristina. Que direito? Trajetórias e percepções dos usuários no processo de acesso a medicamentos por mandados judiciais em Santa Catarina. Ciência \& Saúde Coletiva, Rio de Janeiro, v.15, n. 1, p. 1665-1672, 2010. Disponível em: <http://www. scielo.br/pdf/csc/v15s1/078.pdf>. http://dx.doi.org/10.1590/S1413-81232010000700078.

LIMA, Viviane M. C. Peregrinação, empoderamento e retrocessos no acesso a medicamentos por via judicial no estado do Amazonas - Brasil. 2009. Dissertação (Mestrado) - Universidade do Vale do Itajaí - Univali, Itajaí, 2009.

LOPES, Luciane C. et al. Uso racional de medicamentos antineoplásicos e ações judiciais no Estado de São Paulo. Revista de Saúde Pública, v. 44, n. 4, p. 620-628, ago. 2010. Disponível em: <http://www.scielo.br/pdf/rsp/v44n4/05.pdf>. http://dx.doi.org/10.1590/S0034-89102010000400005. 
LOYOLA, Maria Andréa. Medicamentos e saúde pública em tempos de AIDS: metamorfoses de uma política dependente. Ciência \& Saúde Coletiva, Rio de Janeiro, v. 13, p. 763-778, jun. 2008. Disponível em: <http://www.scielo.br/pdf/csc/v13s0/a27v13s0.pdf >. http://dx.doi.org/10.1590/S1413-81232008000700027.

MACEDO, Eloisa I. de; LOPES, Luciane C.; BARBERATO-FILHO, Silvio. Análise técnica para a tomada de decisão do fornecimento de medicamentos pela via judicial. Revista de Saúde Pública, São Paulo, v. 45, n. 4, p. 706-713, 2011. Disponível em: <http://www.scielo.br/pdf/ rsp/v45n4/2603.pdf>. http://dx.doi.org/10.1590/S0034-89102011005000044.

MACHADO, Felipe R. de S.; DAIN, Sulamis. A audiência pública da saúde: questões para a judicialização e para a gestão de saúde no Brasil. Revista de Administração Pública, v. 46, n. 4, p. 1017-1036, jul./ago. 2012. Disponível em: <http://www.scielo.br/pdf/rap/v46n4/a06v46n4. pdf>. http://dx.doi.org/10.1590/S0034-76122012000400006.

MACHADO, Marina A. de A. Acesso a medicamentos via Poder Judiciário no Estado de Minas Gerais. 2010. Dissertação (Mestrado) - Universidade Federal de Minas Gerais - UFMG, Belo Horizonte, 2010.

. et al. Judicialização do acesso a medicamentos no Estado de Minas Gerais, Brasil. Revista de Saúde Pública, São Paulo, v. 45, n. 3, p. 590-598, 2011. Disponível em: <http://www. scielo.br/pdf/rsp/v45n3/2403.pdf>. http://dx.doi.org/10.1590/S0034-89102011005000015.

MARQUES, Rosa Maria; MENDES, Áquila. Atenção Básica e Programa de Saúde da Família (PSF): novos rumos para a política de saúde e seu financiamento? Ciência \& Saúde Coletiva, São Paulo, v. 8, n. 2, p. 403-415, 2003. Disponível em: <http://www.scielo.br/pdf/csc/v8n2/ a07v08n2.pdf>. http://dx.doi.org/10.1590/S1413-81232003000200007.

MARQUES, Silvia Badim; DALLARI, Sueli G. Garantia do direito social à assistência farmacêutica no Estado de São Paulo. Revista de Saúde Pública, v. 41, n. 1, p. 101-107, fev. 2007. Disponível em: <http://www.scielo.br/pdf/rsp/v4ln1/15.pdf>.http://dx.doi.org/10.1590/S0034-89102007000100014.

MAZZA, Fabio Ferreira. Os impasses entre a judicialização da saúde e o processo orçamentário sob a responsabilidade fiscal: uma análise dos fundamentos decisórios do Supremo Tribunal Federal. 2013. Dissertação (Mestrado) - Faculdade de Saúde Pública, Universidade de São Paulo, São Paulo, 2013. Disponível em: <http://www.teses.usp.br/teses/disponiveis/6/6135/ tde-21052013-162419/>. Acesso em: 15 abr. 2014.

MEINERS, Constance M. M. de A. Patentes farmacêuticas e saúde pública: desafios à política brasileira de acesso ao tratamento anti-retroviral. Cadernos de Saúde Pública, Rio de Janeiro, v. 24, n. 7, p. 1467-1478, jul. 2008. Disponível em: <http://www.scielo.br/pdf/csp/v24n7/02. pdf>. http://dx.doi.org/10.1590/S0102-311X2008000700002.

MESSEDER, Ana Márcia; OSORIO-DE-CASTRO, Claudia G. S.; LUIZA, Vera L. Mandados judiciais como ferramenta para garantia do acesso a medicamentos no setor público: a experiência do Estado do Rio de Janeiro, Brasil. Cadernos de Saúde Pública, Rio de janeiro, v.21, n. 2, p. 525-534, mar./abr. 2005. Disponível em: <http://www.scielo.br/pdf/csp/v21n2/19. pdf>. http://dx.doi.org/10.1590/S0102-311X2005000200019. 
NOGUEIRA, Danielle C. B. A efetivação do direito à saúde: fornecimento judicial de medicamentos. 2011. Dissertação (Mestrado) - Universidade Federal do Maranhão, São Luís, 2011.

PANDOLFO, Mércia; DELDUQUE, Maria Célia; AMARAL, Rita G. Aspectos jurídicos e sanitários condicionantes para o uso da via judicial no acesso aos medicamentos no Brasil. Revista de Salud Pública, Bogotá, v.14, n. 2, p. 340-349, mar./abr. 2012. Disponível em: <http://www.scielosp.org/pdf/rsap/v14n2/v14n2a14.pdf>. http://dx.doi.org/10.1590/S0124-00642012000200014.

PEPE, Vera Lúcia E. et al. A judicialização da saúde e os novos desafios da gestão da assistência farmacêutica. Ciência \& Saúde Coletiva, Rio de Janeiro, v. 15, n. 5, p. 2405-2414, ago. 2010. Disponível em: <http://www.scielo.br/pdf/csc/v15n5/v15n5a15.pdf>. http://dx.doi.org/10.1590/S1413-81232010000500015.

et al. Caracterização de demandas judiciais de fornecimento de medicamentos "essenciais" no Estado do Rio de Janeiro, Brasil. Cadernos de Saúde Pública, São Paulo, v. 26, n. 3, p. 461-471, 2010. Disponível em: <http://www.scielo.br/pdf/csp/v26n3/04.pdf>. http://dx.doi.org/10.1590/S0102-311X2010000300004.

SANT'ANA, João Mauricio B. Essencialidade e assistência farmacêutica: um estudo exploratório das demandas judiciais individuais para acesso a medicamentos no Estado do Rio de Janeiro, Fiocruz. 2009. Dissertação (Mestrado) — Fiocruz, Rio de Janeiro, 2009.

et al. Racionalidade terapêutica: elementos médico-sanitários nas demandas judiciais de medicamentos. Revista de Saúde Pública, São Paulo, v. 45, n. 4, p. 714-721, ago. 2011. Disponível em: <http://www.scielo.br/pdf/rsp/v45n4/2517.pdf>. http://dx.doi.org/10.1590/S0034-89102011005000042.

SARTÓRIO, Maria José. Política de medicamentos excepcionais no Espírito Santo: a questão da judicialização da demanda. 2004. Dissertação (Mestrado) - Universidade Federal do Rio Grande do Sul - UFRGS, Porto Alegre, 2004.

SOARES, Jussara C. R. de S.; DEPRÁ, Aline S. Ligações perigosas: indústria farmacêutica, associações de pacientes e as batalhas judiciais por acesso a medicamentos. Physis: revista de saúde coletiva, Rio de Janeiro, v. 22, n. 1, p. 311-329, 2012. Disponível em: <http://www.scielo. br/pdf/physis/v22n1/v22n1a17.pdf >. http://dx.doi.org/10.1590/S0103-73312012000100017.

STAMFORD, Artur; CAVALCANTI, Maísa. Decisões judiciais sobre acesso aos medicamentos em Pernambuco. Revista de Saúde Pública, São Paulo, v.46, n. 5, p. 791-799, out. 2012. Disponível em: <http://www.scielo.br/pdf/rsp/v46n5/05.pdf>. http://dx.doi.org/10.1590/S0034-89102012000500005.

TANAKA, Oswaldo Y. A judicialização da prescrição medicamentosa no SUS ou o desafio de garantir o direito constitucional de acesso à assistência farmacêutica. Revista de Direito Sanitário, São Paulo, v. 9, n. 1, p. 137-143, 2008. Disponível em: <http://www.revistas.usp. br/rdisan/article/view/13109>. http://dx.doi.org/10.11606/issn.2316-9044.v9i1p139-143. 
VENTURA, Miriam et al. Judicialização da saúde, acesso à justiça e a efetividade do direito à saúde. Physis: revista de saúde coletiva, Rio de Janeiro, v. 20, n. 1, p. 77-100, 2010. Disponível em: <http://www.scielo.br/pdf/physis/v20n1/a06v20n1.pdf>. http://dx.doi.org/10.1590/S0103-73312010000100006.

VIANNA, Luiz J. Werneck; BURGOS, Marcelo; SALLES, Paula. Dezessete anos de judicialização da política. Cadernos CEDES, 2006. Disponível em: <http://www.cis.puc-rio. $\mathrm{br} / \mathrm{cis} /$ cedes/PDF/09janeiro\%20fevereiro/Caderno\%20no13.df $>$. Acesso em: 25 set. 2015.

VIEIRA, Fabiola S. Ações judiciais e direito à saúde: reflexão sobre a observância aos princípios do SUS. Revista de Saúde Pública, São Paulo, v. 42, p. 365-369, 2008. Disponível em: <http://www.scielo.br/pdf/rsp/2008nahead/6847.pdf>. Acesso em: 25 set. 2015.

; ZUCCHI, Paola. Distorções causadas pelas ações judiciais à política de medicamentos no Brasil. Revista de Saúde Pública, São Paulo, v. 41, n. 2, p. 214-222, 2007. Disponível em: <http://www.scielo.br/pdf/rsp/v41n2/5587.pdf>. http://dx.doi.org/10.1590/S0034-89102007000200007.

VILAS BÔAS, Ana Luiza Queiroz; PAIM, Jairnilson Silva. Práticas de planejamento e implementação de políticas no âmbito municipal." Cadernos de Saúde Pública 24, n. 5, p. 1239-1250, jun. 2008. Disponível em: <http://www.scielo.br/pdf/csp/v24n6/05.pdf>. http://dx.doi.org/10.1590/S0102-311X2008000600005.

Teresa Robichez Machado - Doutoranda em Bioética, Ética Aplicada e Saúde Coletiva pela Fundação Oswaldo Cruz; mestre em Teoria do Estado e Direito Constitucional pela Pontifícia Universidade Católica do Rio de Janeiro. Chefe da Assessoria Jurídica da Diretoria Científica e de Desenvolvimento Tecnológico da Financiadora de Estudos e Projetos. Rio de Janeiro/ RJ, Brasil.E-mail: trobichez@yahoo.com.br. 